\title{
Grandes lecciones de historia patria
}

\author{
Dr. Juan Durán Luzioi, Universidad Nacional \\ Recibido: 16/3/2015 \\ Aceptado: 18/05/2015
}

\section{SER Y SER VISTO}

El reconocido padre de la historiografía costarricense, León Fernández Bonilla (1840-1887) cuenta lo siguiente:

Cuando apenas era yo un niño, entre los papeles que mi querido padre, don José León Fernández dejó al morir, encontré algunos manuscritos relativos a la historia de Costa Rica que contenían la narración de los principales sucesos políticos acaecidos durante los años de 1835 a 1842, en que él mismo tomó parte muy activa. Su lectura hizo más tarde nacer en mí el natural deseo de conocer la historia de nuestra patria anterior aquellas fechas. Traté desde entonces de procurarme algún libro que pudiera satisfacer mi curiosidad -continúa Fernández; pero mi decepción no fue pequeña cuando, al tomar informes de cualquiera obra especial que se ocupara de la historia de Costa Rica, recibí siempre la misma contestación: "no la hay" (1883).

La época colonial, pues, los siglos anteriores a la Independencia que interesaban a don León Fernández, parecían no existir. Esa laguna fue para el historiador en ciernes un desafío y una invitación. Poco después se traslada a Guatemala para estudiar Derecho, pero la afición incesante lo llevaría a los ricos archivos de esa antigua capitanía general, donde comenzó a llenar aquel vacío que lo inquietaba.

Más tarde, como ministro de Costa Rica ante varias cortes europeas, aprovechaba todo el tiempo que pudiese para recorrer las grandes bibliotecas nacionales o para instalarse en Sevilla, cerca del Archivo de Indias, y buscar allí pacientemente escritos relativos a la Nueva Cartago y Costa Rica. Algunas veces se hizo acompañar de su hijo, Ricardo Fernández Guardia, quien comenzaba a forjarse así en el oficio de historiador.

De ese arduo y prolongado trabajo de búsqueda, transcripción y edición de manuscritos, nace la monumental Colección de documentos para la historia de Costa Rica, la cual, en 10 tomos, comenzó a ver la luz en 1881,

i Juan Durán Luzio es doctor en Literatura Románica, graduado de la Cornell University,

Estados Unidos. Se desempeña como profesor catedrático de la Escuela de Literatura y

Ciencias del Lenguaje de la Universidad Nacional. Es autor de numerosos libros y artículos reconocidos.

Juan Durán Luzio. Grandes lecciones de historia patria. Revista Comunicación Año 36, vol. 24, núm. 1. Enero - julio, 2015. Tecnológico de Costa Rica. ISSN Impreso: 0379-3974/ e-ISNN: 1659-3820 
pero la muerte de Fernández interrumpió esa misión en 1887. Sin embargo, la misión la completó el hijo discípulo en 1907 al publicar los otros cinco tomos que su padre había planificado y compilado.

¿Cuánto esfuerzo y entrega, invirtió León Fernández Bonilla para reunir esos viejos papeles que daban debida cuenta de lo sucedido en estas tierras desde la visita de Cristóbal Colón hasta la Independencia? Mucho esfuerzo sin duda, pero la deuda con la Colonia había sido honrosamente saldada; la época de dominación española que era entonces una total desconocida, apenas una nebulosa imprecisa antes de esos 10 tomos, pasaba a ser, a existir y ya podía ser vista, conocida, leída y estudiada y recreada por quien se interesase.

\section{PASIÓN Y COMPILACIÓN}

Así las cosas, es justo preguntarnos: ¿qué conduce a una persona a buscar por meses, por años, por décadas los escritos de otra persona o sobre esa otra persona para llegar a conocerla mejor, para despejar los decursos de su vida o los de su país? ¿Qué lleva a un investigador a juntar y ordenar con delicadeza y cariño aquellos viejos libros, cartas, papeles, carpetas varias, que hablan del otro o de su tiempo? Creo que solo la palabra pasión se puede utilizar para explicar esta otra demencia creativa y absorbente, pesada a veces como una enfermedad incurable. No perdamos de vista, para tratar de explicar parte de este sublime mal, que esos libros, papeles y datos se hallaban a menudo a miles de kilómetros, y hubo necesidad de buscarlos venciendo fronteras, climas y guardianes, puesto que no siempre fue Google la distancia más corta entre dos abismos del saber. La pasión, pues, parecer ser el vehículo y el combustible de ese viaje apasionante y demencial.

\section{LA VIDA POR LA HISTORIA}

Se puede deducir, con justicia, que hay seres que han entregado buena parte de sus vidas por el estudio de la historia, por conocer, entender y hacer más comprensible el pasado de los suyos. Se dice que esta tendencia humana se remonta a los inicios de la cultura escrita, y tal vez a antes.

He aquí, que hoy estamos ante dos hombres que han entregado tal vez las mejores energías de su vida intelectual a esa milenaria pasión. Estos dos hombres apasionados se han encontrado en sus labores para el bien de todos nosotros, para el bien del país: Armando Vargas Araya y Raúl Aguilar Piedra sintieron el desafío de levantar el manto que cubría una existencia tan ilustre como la de Juan Rafael Mora Porras, una presencia mayor que, sin embargo, era apenas conocida. Gracias a ellos Juan Rafael Mora comienza a ser visto, a respirar una más completa nueva vida.

El primer tomo de los dos que saludamos en esta ocasión, se titula Palabra viva del Libertador. Legado ideológico y patriótico del Presidente Juan Rafael Mora para la Costa Rica en devenir, en él sus autores se han propuesto poner de manifiesto quién fue Juan Rafael Mora, y para esto han recurrido a sus propias palabras. En tal misión han rastreado y logrado un acopio de 140 textos que llevan su firma y se extienden desde que Mora tenía 24 años hasta unas pocas horas antes de ser ejecutado, a los 46 años de su edad. Los textos se reproducen completos y la mayoría de ellos con notas explicativas al pie de ayuda para el lector.

En estas páginas el ser de este hombre se va concretando paso a paso, y sobresale un proceso: el ver cómo se fue haciendo por su carácter laborioso y ordenado, y por su patriotismo: entregado al comercio desde la adolescencia no pierde, sin embargo ocasión de servir a su país, y para eso, por ejemplo, pide en carta al Mentor Costarricense, cuando apenas tiene 29 años de edad que se creen en el país tribunales de segunda instancia para servir mejor a la administración de justicia de su joven república. O como cuando ya en su primera presidencia inaugura, el 15 de setiembre de 1850, las Facultades de Medicina y de Ciencias Legales y Políticas en la renovada Casa de Estudios de Santo Tomás; allí comenzó su discurso con estas notables frases el cual afirman Vargas. A. y Aguilar. R. (2014):

"Hoy es el aniversario de nuestra independencia de la España, día solemne y memorable en los fastos de la República. Grandes y duraderos son los bienes que hemos alcanzado y mayores los que promete el porvenir a nuestra futuras generaciones."

Y así, de tal modo, va cobrando forma tangible la figura de un desconocido josefino, el joven autodidacta que llega a la arena política porque así se lo demandan sus compatriotas, quienes lo habían elegido ya en 1843 vicepresidente de la Asamblea Constituyente del Estado, luego diputado al Congreso Nacional, vicepresidente del Estado en 1847 y en diciembre de 1849 es electo por primera vez a la Presidencia de la República.

Gobernante que se ve pocos años después en la difícil obligación de conducir a su pueblo a una guerra en el papel de David contra un Goliat que lo desprecia, y 
quien finalmente, un aciago día en Puntarenas, ofrece su sangre ante sus captores para que no corriera la sangre de otros costarricenses, conciudadanos suyos que desde entonces ya le llamaban don Juanito.

Al finalizar el libro la deuda está saldada: Mora es, existe y aquí quedará, por fin, en estas páginas, como el ser cotidiano, como padre de familia y como gobernante, para seguir orientando a sus compatriotas. Sí, se ha pagado una deuda a la historia: la silueta que representaba a Juan Rafael Mora, apenas visible, ha sido cincelada a una forma final y adecuada. Al respecto: una rica cronología de 70 páginas termina por dar precisión y orden a esta relación que se ha hecho por sí misma, por los textos que este gran costarricense selló con su firma, como una suerte de autobiografía narrada sin pretensiones de grandeza ni egoísmo.

En el otro libro presentado esta noche, Vargas Araya ha editado cuidadosamente una serie de documentos sobre el modo cómo fue visto el Presidente Mora por algunos de sus más ilustres coetáneos, y luego por la posteridad, textos surgidos estos últimos de juicios emitidos en varios países de Occidente.

La primera sección de este tomo se titula Los contemporáneos y comprende 42 textos escritos por personas que conocieron a Juan Rafael Mora o son páginas que por aquellos días se refirieron al tres veces presidente de Costa Rica. Estas páginas admirativas y elogiosas bastarían para anular los reproches que a sus gestiones se hacen de manera inconsulta.

Al respecto son muy conmovedoras, igualmente, aquellas palabras que lamentaron su injusta muerte, escritas algunas en Estados Unidos, en El Salvador, en Panamá, en Francia, en Chile.

Más estimables resultan las opiniones de quienes lo conocieron personalmente porque ahí está el costarricense devoto de su país, el ser hospitalario y el republicano inclaudicable, el gobernante siempre leal a sus convicciones democráticas.

\section{PRESENCIA FUGAZ, PRESENCIA PERMANENTE}

Simón Bolívar es una presencia permanente en la historia de Venezuela; Benito Juárez es una presencia permanente en la historia de México, como lo es Abraham Lincoln en la de los Estados Unidos de América. José de San Martín es una figura imborrable en la historia de la nación Argentina, como lo es Bernardo O'Higgins en la de Chile. Todos ellos permanecen activos en la memoria de sus pueblos; y prácticamente todas sus palabras han sido recogidas y publicadas con esmero para que esa memoria colectiva no decaiga y esas palabras sirvan a la educación y formación de las siguientes generaciones.

Paso ahora a otra breve reflexión acerca de la representación que la figura y la obra del presidente Mora han recibido por parte de los escritores e historiadores locales que se han ocupado del pasado costarricense.

Si no es Juan Rafael Mora una presencia permanente y vigente en la historia de Costa Rica, ¿no debería serlo? Por supuesto que sí, dígase lo que se diga; sin embargo, si Mora Porras ha permanecido en la memoria de los costarricenses ha sido más -me parece- por un hecho afectivo que por conocimiento de sus notables obras. Es justo decirlo: el siglo XIX en general es muy bien conocido por nuestros estudiosos del pasado: la década que sigue a la independencia, los años de la Confederación de Repúblicas Centroamericanas, los planes y la obra de Braulio Carrillo, las ideas de Castro Madriz, y ni se diga de las lúcidas y abundantes páginas sobre la economía del café, anunciando la llegada de la modernidad al país, los hechos militares de la Campaña Nacional, y sus consecuencias sobre el río San Juan, los años de Tomás Guardia y la era liberal han recibido especial atención de los historiadores.

Es triste decirlo, pero a nadie sorprenderá que la figura de Mora, a pesar de su grandeza y de su popularidad ha sido hasta hace muy poco solo la de una silueta en la narrativa histórica del país, y apenas una sombra lejana en su literatura. Aunque desde años atrás se han tratado de emprender las obras que Vargas Araya y Aguilar Piedra presentan esta noche, el proyecto quedó solo en proyecto; además de difíciles, las causas de tal postergación son variadas y polémicas. Esperemos que desde ahora en adelante, por obra y gracia de estos textos, esta presencia fugaz, necesaria para la educación, la cultura y la soberanía del país se convierta en presencia permanente e indeleble porque, ¿no es esta labor un acto de defensa de la Patria, un homenaje a su libertad?

\section{REFERENCIAS BIBLIOGRÁFICAS}

Fernández, L. (1883).Colección de documentos para la historia de Costa Rica. San José: Imprenta Nacional.

Meléndez, C. (1876). Palabras Preliminares. San José: Editorial Costa Rica.

Vargas. A. y Aguilar. R. (2014). Palabra viva del Libertador. Legado ideológico y patriótico del Presidente Juan Rafael Mora para la Costa Rica en devenir. San José: Editorial Eduvisión. 